\title{
Erratum to: Management of headache disorders in the Emergency Department setting
}

Elisa Pari $^{1}$ • Fabrizio Rinaldi ${ }^{1} \cdot$ Stefano Gipponi $^{1}$.

Elisabetta Venturelli ${ }^{1}$ Paolo Liberini ${ }^{1} \cdot$ Renata Rao $^{1}$. Alessandro Padovani ${ }^{1}$

Published online: 20 May 2015

(C) Springer-Verlag Italia 2015

\section{Erratum to: Neurol Sci}

DOI 10.1007/s10072-015-2148-7

Unfortunately, authors' surnames precede authors' names in the original publication of the article.

The correct authors names and surnames should be as follows:

Elisa Pari, Fabrizio Rinaldi, Stefano Gipponi, Elisabetta Venturelli, Paolo Liberini, Renata Rao, Alessandro Padovani. The original article has been updated accordingly.

The online version of the original article can be found under doi:10. 1007/s10072-015-2148-7.

Elisa Pari

pari.elisa@libero.it

1 Neurological Department, University of Brescia, Brescia,

Italy 